\title{
Robotic Pancreatectomy: What is the Current Evidence?
}

Lee $\mathbf{S Y}^{1,2}$ and Goh BK ${ }^{1,2^{*}}$

${ }^{1}$ Department of Hepatopancreatobiliary and Transplant Surgery, Singapore General Hospital, Singapore

${ }^{2}$ Duke -National University of Singapore (NUS) Medical School, Singapore

*Corresponding author: Goh BK, Department of Hepatopancreatobiliary and Transplant Surgery, General Hospital, Singapore, Tel: +6563265564; E-mail: bsgkp@hotmail.com

Received date: Nov 30, 2015; Accepted date: Dec 19, 2015; Published date: Dec 21, 2015

Copyright: (C) 2015 Goh BK, et al. This is an open-access article distributed under the terms of the Creative Commons Attribution License, which permits unrestricted use, distribution, and reproduction in any medium, provided the original author and source are credited.

\begin{abstract}
Laparoscopic pancreatectomy has evolved from resection of benign lesions to the treatment of malignant lesions without compromising patient safety and oncologic principles. Driven by the technical shortcomings of laparoscopic surgery, robotic pancreatectomy is the latest development in this evolution. Presently, there are limited but increasing amount of data comparing the outcomes of the various approaches for pancreatectomy: robotic versus laparoscopic and open pancreatectomy. Most studies to date are single large institutional retrospective case series or case-control studies reporting on the safety and feasibility of robotic pancreatectomies but most fail to address key issues like cost-benefit ratio and selection biases. Hence, presently, there is only low level evidence from retrospective studies supporting the use of robotic pancreatectomy. These studies have demonstrated that robotic pancreatectomy is safe and feasible with outcomes at least comparable to conventional laparoscopy and open surgery. There is some evidence suggesting that robotic surgery may decrease the learning curve and conversion rate in minimally invasive pancreatic surgery. Further research is needed to evaluate and compare the effectiveness of robotic pancreatectomy with conventional laparoscopy and open surgery.
\end{abstract}

Keywords: Robotic pancreatectomy; Minimally invasive surgery; DaVinci; Robot; Laparoscopic pancreatectomy

\section{Introduction}

Laparoscopic pancreatic resection remains one of the newer developments in pancreatic surgery although it was first reported 2 decades ago in 1994 by Cushieri [1]. Following the introduction of robotic abdominal surgery, the first series of 13 robotic pancreatic resections was published by Giulianotti et al. [2]. Laparoscopic pancreatic resections were initially performed for benign lesions requiring left-sided pancreatosplenectomies. However as experience, surgical techniques and equipment improved; its indications have been expanded to malignant neoplasms and more technically demanding procedures such pancreaticoduodenectomies and spleen-preserving pancreatectomies. Despite the advantages associated with laparoscopic surgery such as decreased pain, diminished blood loss, decreased hospital stay and improved cosmesis [3]; the jury is still out there with regards to the definite role and cost-benefit ratio of laparoscopy for complex surgical procedures such as pancreatectomies. Presently, the role of robotic pancreatic surgery remains even more poorly defined as there is limited evidence available in the current literature demonstrating its clinical utility.

As custodians of our patients' health, questions will always arise when new technology or innovation enters our clinical practice. One key question would be: Does it really benefit our patients and improve outcomes? The technology from which the robotic surgical platform arose from military research and research for space exploration. Currently, the $\mathrm{DaVinci}^{\otimes}$ surgical system by Intuitive Surgical is the dominant system. It consists of a three or four-armed bedside robot which is operated by a surgeon who sits at a console $[4,5]$. In theory, robotic surgery should retain the benefits of laparoscopic techniques with regard to smaller incisions, shorter hospitalization periods, less physiological stress induced by surgery and quicker patient recovery. Additionally, there are several potential technical advantages of robotic surgery over conventional laparoscopy [6]. This includes a high definition 3-dimensional (3D) view, tremor filtration, motion scaling, improved surgeon ergonomics and significant increased range of motion due to an internal articulated EndoWrist $[7,8]$. These features are obviously attractive to pancreatic surgeons due to the intricate nature and the complexity of pancreatic resections. However, this new platform has also raised concerns among surgeons on the lack of tactile feedback, higher costs and longer surgical time as compared to conventional laparoscopy or open surgery [9].

To objectively examine the evidence for robotic pancreatectomy, one should ideally review the different forms of resections separately, namely distal pancreatectomy (DP) with and without splenic preservation, pancreatoduodenectomy (PD) and others procedures such as central pancreatectomy (CP) and total pancreatectomy (TP). To date, there have been several relatively large surgical series which may shed some light on this issue [10-13].

The adoption of the laparoscopic approach for DP especially when performed with a splenectomy has become more widely accepted compared to PD or CP. This is because it is a relatively technically less demanding procedure as it does not require any reconstruction or anastomosis. Ever since the first reported robotic DP; several institutions have published their experience and outcomes with robotic DP $[9,14]$. Currently, there is limited evidence comparing open DP and/or laparoscopic DP vs. robotic DP. To date, there are only 5 retrospective and 1 prospective comparative studies published in the literature [9,15-20] (Table 1). Some potential benefits of the robotic approach over conventional laparoscopic DP which have been reported include a higher rate of splenic preservation (vessel 
Page 2 of 5

preserving) and a lower conversion rate [10,15,21]. The increased rate of splenic vessel preservation after DP has been attributed to the improved dexterity and precision of the robotic arms when working in tight spaces $[10,15,21]$. However, despite its many theoretical technical advantages, robotic DP remains a complex procedure associated with a significant learning curve. In a recent study of 100 consecutive robotic DP, the learning curve of robotic DP with regards to operation time was reported to be optimized at about 40 cases [22]. This relatively long learning curve for a relatively rare surgical procedure poses a major obstacle to the widespread adoption of robotic DP world-wide. However, it is highly likely that the learning curve could potentially be shortened in future adopters with increasing familiarity with the platform and standardization of surgical techniques [22]. The Memorial Sloan Kettering Cancer Center recently published their 14 year experience of over 800 DP comparing open, laparoscopic and robotic DP and found that robotic and laparoscopic DP were comparable with respect to most perioperative outcomes, with no clear advantage of one approach over the other [9]. Today, DP remains a surgical procedure associated with a high morbidity rate especially from postoperative pancreatic fistula regardless of the surgical approach [23].

\begin{tabular}{|c|c|c|c|c|c|c|c|c|c|c|c|c|c|}
\hline $\begin{array}{l}\text { Author } \\
\text { (Year) }\end{array}$ & Country & Approach & $\mathbf{N}$ & $\begin{array}{l}\text { Mean } \\
\text { operati } \\
\text { ve time } \\
\text { (min) }\end{array}$ & $\begin{array}{l}\text { EBL } \\
(\mathrm{ml})\end{array}$ & $\begin{array}{l}\text { Conver } \\
\text { sion } \\
\text { rate, } \\
(\%)\end{array}$ & $\begin{array}{l}\text { Spleen } \\
\text { preservat } \\
\text { ion rate } \\
(\%)\end{array}$ & $\begin{array}{l}\text { R0 } \\
\text { resection, } \\
\%\end{array}$ & $\begin{array}{l}\text { Morbidity } \\
(\%)\end{array}$ & $\begin{array}{l}\text { Mortality } \\
\text { (\%) }\end{array}$ & $\begin{array}{l}\text { Pancreati } \\
\text { c fistula } \\
\text { (\%) }\end{array}$ & $\begin{array}{l}\text { Length of } \\
\text { stay } \\
\text { (days) }\end{array}$ & $\begin{array}{l}\text { Cost } \\
\text { (USD) }\end{array}$ \\
\hline \multirow{3}{*}{$\begin{array}{l}\text { Waters et } \\
\text { al. [16] }\end{array}$} & \multirow{3}{*}{ USA } & Open & 32 & $245^{*}$ & 279 & N.A & $14^{\star}$ & 100 & 18 & 0 & 18 & $8^{*}$ & $\$ 16059$ \\
\hline & & $\begin{array}{l}\text { Laparoscopi } \\
\text { c }\end{array}$ & 28 & $222^{*}$ & 667 & 11 & $28^{*}$ & 82 & 33 & 0 & 11 & $6^{*}$ & $\$ 12986$ \\
\hline & & Robotic & 17 & $298^{*}$ & 681 & 12 & $65^{*}$ & 100 & 18 & 0 & 0 & $4^{*}$ & $\$ 10588$ \\
\hline \multirow[t]{2}{*}{$\begin{array}{l}\text { Kang et al. } \\
{[17]}\end{array}$} & \multirow[t]{2}{*}{ Korea } & $\begin{array}{l}\text { Laparoscopi } \\
\text { c }\end{array}$ & 25 & $258^{*}$ & - & NR & $64^{*}$ & NR & 16 & 0 & NR & 7.1 & $\$ 3861$ \\
\hline & & Robotic & 20 & $348^{*}$ & - & NR & $95^{*}$ & NR & 10 & 0 & NR & 7.3 & $\$ 8304$ \\
\hline \multirow[t]{2}{*}{$\begin{array}{l}\text { Daouadi et } \\
\text { al. [18] }\end{array}$} & \multirow[t]{2}{*}{ USA } & $\begin{array}{l}\text { Laparoscopi } \\
\text { c }\end{array}$ & 94 & $372^{*}$ & 150 & $16^{*}$ & 18 & 64 & 64 & 1.1 & 41 & 7.1 & NR \\
\hline & & Robotic & 30 & $293^{*}$ & 150 & $0^{*}$ & 7 & 100 & 66 & 0 & 46 & 6.1 & NR \\
\hline \multirow{2}{*}{$\begin{array}{l}\text { Lai et al. } \\
{[19]}\end{array}$} & \multirow{2}{*}{$\begin{array}{l}\text { Hong } \\
\text { Kong, } \\
\text { China }\end{array}$} & $\begin{array}{l}\text { Laparoscopi } \\
\text { c }\end{array}$ & 17 & $172^{*}$ & 282 & NR & 41.2 & NR & 41.2 & 0 & 35.3 & 14.2 & NR \\
\hline & & Robotic & 9 & $242^{*}$ & 104 & NR & 66.7 & NR & 55.6 & 0 & 44.4 & 8 & NR \\
\hline \multirow{3}{*}{$\begin{array}{l}\text { Lee et al. } \\
\text { [9] }\end{array}$} & \multirow{3}{*}{ USA } & Open & 637 & $185^{*}$ & $596^{*}$ & N.A & 14 & 88 & 40 & 0.6 & 12 & 7 & NR \\
\hline & & $\begin{array}{l}\text { Laparoscopi } \\
\text { c }\end{array}$ & 131 & $193^{*}$ & $262^{*}$ & $41(31)$ & 22 & 100 & 32 & 0 & 8 & 5 & NR \\
\hline & & Robotic & 37 & $213^{*}$ & $193^{*}$ & $14(38)$ & 8 & 100 & 32 & 0 & 8 & 5 & NR \\
\hline \multirow{2}{*}{$\begin{array}{l}\text { Butturini et } \\
\text { al. [20] }\end{array}$} & \multirow[t]{2}{*}{ Italy } & $\begin{array}{l}\text { Laparoscopi } \\
\text { c }\end{array}$ & 21 & 195 & BT: $0 \%$ & 4.7 & 19 & NR & 71.4 & 0 & 57.1 & 7 & $1500^{*}$ \\
\hline & & Robotic & 22 & 265 & $\begin{array}{l}\text { BT: } \\
13 \%\end{array}$ & 4.5 & 27.3 & NR & 68.2 & 0 & 50 & 7 & $3000^{*}$ \\
\hline
\end{tabular}

Abbreviations: EBL: Estimated blood loss; ${ }^{*} \mathrm{p}<0.05$; NR: Not reported; BT: Blood Transfusion (Intraoperative); \#: Euros; NA: Not Applicable

Table 1: Summary of studies comparing Robotic distal pancreatectomies vs. Open and/or Laparoscopic distal pancreatectomies

In contrast to laparoscopic DP, the adoption of laparoscopic PD has been limited. From 2005-2010, it was estimated that more than a quarter of DP were performed laparoscopically in North America [24]. In contrast, unlike the ubiquitous adoption of laparoscopic DP, laparoscopic PD had a much slower adoption rate most likely due to its steeper learning curve. Laparoscopic PD was first reported by Garner and Pomp in 1994 [9]. In 2012, it was reported that only 7 centers had an experience of more than 30 patients who had undergone laparoscopic PD, with very few surgeons in the world acquiring a significant experience with the procedure $[25,26]$. Interestingly, the adoption of robotic PD in comparison with laparoscopic PD has increased at a relatively more rapid rate compared to the frequency of adoption of robotic DP versus laparoscopic DP. In 2001, Giulianotti et al. first reported robotic $\mathrm{PD}$ in an initial series of 8 patients with a morbidity rate of $37.5 \%$. More recently, investigators from the University of Pittsburgh published the largest series of robotic pancreatic resections to-date, which included $132 \mathrm{PD}[2,14]$. Although it is impossible to determine the exact reasons behind this observation; it is not implausible to postulate that a major reason could be due to the enabling effect of the robotic system over conventional laparoscopy for surgeons resulting in a gentler learning curve for complex pancreatic operations. Most surgeons would agree that the robot is superior with regards to performing laparoscopic maneuvers such as precise suturing and fine dissection which is essential when performing a PD. The morbidity of $\mathrm{PD}$ is largely associated with the incidence of pancreatic fistula and the assistance of the robot may 
potentially improve the precision and dexterity when performing the pancreato-enteric reconstruction, although this have yet to be proven [15]. A recent meta- analysis comparing open and robotic pancreatectomy favored the latter approach with a risk difference of $12 \%$ in both re-operation and morbidity rate. However, a major limitation of this meta-analysis was that the study population was heterogeneous and included PD, DP as well as CP cohorts [11]. Another 2 systematic reviews on robotic pancreatectomies were published in 2013. Nigri et al. analyzed 8 studies that compared minimally invasive surgery (MIS) $(n=204)$ vs open PD $(n=419)$, they concluded that there were no significant differences in complications such as pancreatic fistula, delayed gastric emptying, wound infection, reoperation and mortality rates and found that the MIS approach was associated with a greater lymph node harvest with better margins but with longer operating times. However, the authors combined both laparoscopic and robotic approaches as a single MIS group and did not compare between the 2 groups [12]. The other systematic review by Cirocchi et al. which focussed solely on robotic PD included 13 studies with 207 patients, they reported an average R1 resection rate of $9 \%$ and concluded that for highly selected patients, robotic PD is feasible with similar morbidity and mortality compared to open or purely laparoscopic approaches [13] (Table 2).

\begin{tabular}{|c|c|c|c|c|c|c|c|c|c|c|c|c|c|}
\hline $\begin{array}{l}\text { Author } \\
\text { (Year) }\end{array}$ & $\begin{array}{l}\text { Countr } \\
y\end{array}$ & Approach & $\mathbf{N}$ & $\begin{array}{l}\text { Age } \\
\text { (Years) }\end{array}$ & $\begin{array}{l}\text { Mean } \\
\text { operative } \\
\text { time (min) }\end{array}$ & $\begin{array}{l}\text { EBL } \\
(\mathrm{ml})\end{array}$ & $\begin{array}{l}\text { Conversion } \\
\text { rate, } \mathrm{n}(\%)\end{array}$ & $\begin{array}{l}\text { R0 } \\
\text { resection }\end{array}$ & $\begin{array}{l}\text { Harvested } \\
\text { lymph } \\
\text { nodes, } \\
\text { mean (n) }\end{array}$ & $\begin{array}{l}\text { Morbidity } \\
(\%)\end{array}$ & $\begin{array}{l}\text { Mortality } \\
(\%)\end{array}$ & $\begin{array}{l}\text { Pancreatic } \\
\text { fistula (\%) }\end{array}$ & $\begin{array}{l}\text { Length } \\
\text { of stay } \\
\text { (days) }\end{array}$ \\
\hline \multirow{2}{*}{$\begin{array}{l}\text { Buchs } \\
\text { [33] }\end{array}$} & \multirow[t]{2}{*}{ USA } & Open & 39 & $56^{*}$ & $559^{*}$ & $827^{*}$ & N.A & 81.5 & $11^{*}$ & 48.7 & 2.6 & 20.5 & 14.6 \\
\hline & & Robotic & 44 & & & & & & & & & & \\
\hline \multirow[t]{2}{*}{ Zhou [34] } & \multirow[t]{2}{*}{ China } & Open & 8 & 57 & $420^{*}$ & $210^{*}$ & N.A & 83.3 & $N R$ & $75^{*}$ & 0 & 37.5 & $24.3^{*}$ \\
\hline & & Robotic & 8 & 65 & $718^{*}$ & $153^{*}$ & N.A & 100 & $N R$ & $25^{\star}$ & 12.5 & 50 & $16.4^{*}$ \\
\hline \multirow{2}{*}{$\begin{array}{l}\text { Chalikond } \\
\text { a }[35 \pi\end{array}$} & \multirow[t]{2}{*}{ USA } & Open & 30 & 61 & $366.4^{*}$ & 775 & N.A & $87^{*}$ & 11.8 & 43 & 0 & 7 (Grade B) & $13.26^{*}$ \\
\hline & & Robotic & 30 & 62 & $476.2^{*}$ & 485.8 & $3(12)$ & $100^{*}$ & 13.2 & 30 & 4 & $\begin{array}{l}\text { 7(Grade } \\
\text { B/C) }\end{array}$ & $9.79^{*}$ \\
\hline \multirow[t]{2}{*}{$\begin{array}{l}\text { Lai et al. } \\
\text { [19] }\end{array}$} & \multirow[t]{2}{*}{$\begin{array}{l}\text { Hong } \\
\text { Kong }\end{array}$} & Open & 67 & 62.1 & $264.9^{*}$ & 774.8 & N.A & 64.1 & 10 & 49.3 & 3 & 17.9 & $25.8^{*}$ \\
\hline & & Robotic & 20 & 66.4 & $491.5^{*}$ & $247^{*}$ & 5 & 73.3 & 10 & 50 & 0 & 35 & $13.7^{*}$ \\
\hline \multirow{2}{*}{$\begin{array}{l}\text { Hammil et } \\
\text { al. [36 § }\end{array}$} & \multirow[t]{2}{*}{ China } & Open & 69 & 55 & 398 & 450 & N.A & $N R$ & $N R$ & 23 & 1.4 & NR & 7 \\
\hline & & Robotic & 8 & 62.5 & 648 & 256 & $1(11)$ & $N R$ & NR & 25 & 0 & NR & 14 \\
\hline \multirow{2}{*}{$\begin{array}{l}\text { Walsh [37 } \\
\text { đ }\end{array}$} & \multirow[t]{2}{*}{ USA } & Open & 25 & 62 & $364^{*}$ & 840 & N.A & 73 & $N R$ & 44 & 0 & $N R$ & 14 \\
\hline & & Robotic & 25 & 63 & $488^{*}$ & 537 & $3(12)$ & 100 & $N R$ & 32 & 4 & $N R$ & 10 \\
\hline
\end{tabular}

Abbreviations: EBL: Estimated blood loss; "statistically significant, $p<0.05$; NA: Not Applicable; § Published ab NR stracts. T: Possible overlap of patient cohorts; NR: Not reported

Table 2: Summary of studies comparing Open vs. Robotic pancreaticoduodenectomies

The data available for other pancreatic resections via the robotic platform remains limited to small case series and reports. Cheng et al. published their initial experience in 7 patients matched with 36 patients who undergone robotic and open $\mathrm{CP}$ respectively and concluded that patients in the robotic group experienced faster gastrointestinal tract recovery [27]. Similarly, Kang et al. presented a small series of 5 robot-assisted CP and compared it to their open CP experience. The robotic surgery group was associated with a significantly longer operating time but decreased blood loss [28]. In their experience of 250 robotic pancreatic resections, surgeons from the University of Pittsburgh reported a variety of pancreatic procedures such as 13 CPs, 5 TPs, 10 enucleations, 4 Appleby resections and 3 Frey procedures [14]. Based on their experience which is the largest robot pancreatectomy experience to-date, they concluded that robotic pancreatectomy was safe and feasible. They further added that there were no unanticipated risks inherent to this new technology [14]. More recently, there have even been anecdotal reports of robot- assisted pancreatic transplants with 3 cases reported in a recent study [29].

The evidence for robotic pancreatic surgery is culminating but still lacks robust data. Most case series and case control comparison studies unfortunately have failed to address several main issues related to the robotic technology. One of the most important issues is the considerable start-up and high recurring costs associated with this new technology. Presently, the cost-benefit ratio of robotic pancreatic surgery has not been well-studied. Kang et al. reported that the robotic surgery cost was almost 2.5 times that of conventional laparoscopic surgery in Korea [17]. Presently, there is some evidence from retrospective studies that laparoscopic DP is more cost effective than open DP [30]. However, this does not apply to robotic pancreatectomy at present whereby the absolute cost is almost certainly higher than conventional laparoscopy or open surgery. Nonetheless, it is important to note that it is almost inevitable that the cost of robotic surgery would decrease significantly in the near future as it becomes more widely and readily available. Furthermore, the emergence of competing 
companies and robotic systems would almost certainly result in the lowering of costs of robotic surgery which at present is monopolized by a single commercial firm.

A common limitation in all the studies to date reporting on robotic pancreatectomies was that the analyses were all conducted in retrospective patient cohorts. Hence, the reported findings were likely to be limited by selection bias in these non-prospective, nonrandomized studies. The advantages of robotic surgery over laparoscopy and open surgery could be due to selection bias or other confounding factors. For example, the shorter learning curve and decreased conversion rates observed with robotic surgery could be confounded by the fact that more frequently than not, surgeons who begin performing robotic pancreatectomies had already acquired a significant amount of experience in open and conventional laparoscopy before embarking on robotic surgery [31].

Finally, it is important to note that the introduction and adoption of new surgical technology is a complex event and often poorly studied. Unlike other research questions; randomized controlled trials in this aspect are rarely feasible nor realistic due to the inability to truly blind the subjects and investigators and due to the inherent lack of true clinical equipoise [32]. Thus far, the majority of such innovations today are established on the findings of large retrospective experiences. The crux of the matter is that until the cost, accessibility and experience of robotic surgery becomes equitable to laparoscopic surgery, defining the exact role of robotic pancreatectomy today will continue be an ongoing challenge for pancreatic surgeons.

\section{Conclusion}

Presently, there is only low level evidence from retrospective cases series and case-control studies supporting the use of robotic pancreatectomy. These studies have demonstrated that robotic pancreatectomy is safe and feasible with outcomes at least comparable to conventional laparoscopy and open surgery. There is some evidence suggesting that robotic surgery may decrease the learning curve and conversion rate in MIS pancreatic surgery. Further research is needed to evaluate and compare the effectiveness of robotic pancreatectomy with conventional laparoscopy and open surgery.

\section{References}

1. Cuschieri A (1994) Laparoscopic surgery of the pancreas. J R Coll Surg Edinb 39: 178-184.

2. Giulianotti PC, Coratti A, Angelini M, Sbrana F, Cecconi S et al. (2003) Robotics in general surgery: personal experience in a large community hospital. Arch Surg 138: 777-784.

3. Ricci C, Casadei R, Taffurelli G, Toscano F, Pacilio CA, et al. (2015) Laparoscopic Versus Open Distal Pancreatectomy for Ductal Adenocarcinoma: A Systematic Review and Meta-Analysis. J Gastrointest Surg 19: 770-781.

4. Mack MJ (2001) Minimally invasive and robotic surgery. Jama 285: 568-572.

5. Wilson TG (2014) Advancement of Technology and Its Impact on Urologists: Release of the da Vinci Xi. A New Surgical Robot. Eur Urol 66: 793-4.

6. Lendvay TS, Hannaford B, Satava RM (2013) Future of robotic surgery. Cancer J 19: 109-119.

7. Ballantyne GH (2007) Telerobotic gastrointestinal surgery: Phase 2 safety and efficacy. Surg Endosc 21: 1054-1062.
8. Talamini MA, Chapman S, Horgan S, Melvin WS (2003) A prospective analysis of 211 robotic-assisted surgical procedures. Surg Endosc 17: 1521-1524.

9. Lee SY, Allen PJ, Sadot E, D'Angelica MI, DeMatteo RP (2014) Distal pancreatectomy: A single institution's experience in open, laparoscopic and robotic approaches. Journal of the American College of Surgeons 22: 18-27.

10. Joyce D, Morris-Stiff G, Falk GA, El-Hayek K, Chalikonda S (2014) Robotic surgery of the pancreas. World J Gastroenterol 20: 14726-14732.

11. Zhang J, Wu WM, You L, Zhao YP (2013) Robotic versus open pancreatectomy: a systematic review and meta-analysis. Ann Surg Oncol 20: $1774-1780$

12. Nigri G, Petrucciani N, Torre LM, Magistri P, Valabrega S (2014) Duodenopancreatectomy: Open or minimally invasive approach? Surgeon 12: 227-234.

13. Cirocchi R, Partelli S, Trastulli S, Coratti A, Parisi A (2013) A systematic review on robotic pancreaticoduodenectomy. Surg Oncol 22: 238-246.

14. Zureikat AH, Moser AJ, Boone BA, Bartlett DL, Zenati M et al. (2013) 250 Robotic pancreatic resections: Safety and feasibility. Ann Surg 258: 554-559.

15. Zureikat AH, Hogg ME, Zeh HJ (2014) The utility of the robot in pancreatic resections. Adv Surg 48: 77-95.

16. Waters JA, Canal DF, Wiebke EA, Dumas RP, Beane JD (2010) Robotic distal pancreatectomy: Cost effective? Surgery 148: 814-823.

17. Kang CM, Kim DH, Lee WJ, Chi HS (2011) Conventional laparoscopic and robot-assisted spleen-preserving pancreatectomy: Does da Vinci have clinical advantages? Surg Endosc 25: 2004-2009.

18. Daouadi M, Zureikat AH, Zenati MS, Choudry H, Tsung A (2013) Robot-assisted minimally invasive distal pancreatectomy is superior to the laparoscopic technique. Ann Surg 257: 128-132.

19. Lai EC, Tang CN (2013) Current status of robot-assisted laparoscopic pancreaticoduodenectomy and distal pancreatectomy: A comprehensive review. Asian J Endosc Surg 6: 158-164.

20. Butturini G, Damoli I, Crepaz L, Malleo G, Marchegiani G (2015) A prospective non-randomised single-center study comparing laparoscopic and robotic distal pancreatectomy. Surg Endosc 29: 3163-3170.

21. Goh BK, Wong JS, Chan CY, Cheow PC, Ooi LL (2016) First experience with robotic spleen-saving vessel preserving distal pancreatectomy in Singapore: report of 3 consecutive cases. SMJ.

22. Shakir M, Boone BA, Polanco PM (2015) The learning curve for robotic distal pancreatectomy: An analysis of outcomes of the first 100 consecutive cases at a high-volume pancreatic centre. HPB 17: 580-6.

23. Goh BK, Tan YM, Chung YF (2008) Critical appraisal of 232 consecutive distal pancreatectomies with emphasis on risk factors, outcome, and management of the postoperative pancreatic fistula: A 21-year experience at a single institution. Arch Surg 143: 956-65.

24. Velderrain AR, Bowers SP, Goldberg RF, Clarke TM, Buchanan MA (2012) National trends in resection of the distal pancreas. World J Gastroenterol 18: 4342-4349.

25. Gagner M, Pomp A (1994) Laparoscopic pylorus-preserving pancreatoduodenectomy. Surg Endosc 8: 408-410.

26. Kendrick ML (2012) Laparoscopic and robotic resection for pancreatic cancer. Cancer J 18: 571-576

27. Cheng K, Shen B, Peng C, Deng X, Hu S (2013) Initial experiences in robot-assisted middle pancreatectomy. HPB 15: 315-21.

28. Kang CM, Kim DH, Lee WJ, Chi HS (2011) Initial experiences using robot-assisted central pancreatectomy with pancreaticogastrostomy: a potential way to advanced laparoscopic pancreatectomy. Surg Endosc 25: 1101-6.

29. Tzvetanov I, D'Amico G, Bejarano-Pineda L, Benedetti E (2014) Roboticassisted pancreas transplantation: where are we today? Curr Opin Organ Transplant 19: 80-2.

30. Mehrabi A, Hafezi A, Arvin J (2015) A systematic review and metaanalysis of laparoscopic versus open distal pancreatectomy for benign and 
Citation: Goh BK, Lee SY (2015) Robotic Pancreatectomy: What is the Current Evidence?. Adv Robot Autom S2: 004. doi: 10.4172/2168-9695.S2-004

Page 5 of 5

malignant lesions of the pancreas: Its time to randomize. Surgery 157 45-55.

31. Goh BK (2014) Robot-assisted minimally invasive distal pancreatectomy is superior to the laparoscopic technique. Ann Surg.

32. Wilson CB (2006) Adoption of new surgical technology. Bmj 332: 112-114.

33. Buchs NC, Addeo P, Bianco FM, Ayloo S, Benedetti E et al. (2011) Robotic versus open pancreaticoduodenectomy: a comparative study at a single institution. World J Surg 35: 2739-46.

34. Zhou NX, Chen JZ, Liu Q (2011) Outcomes of pancreatoduodenectomy with robotic surgery versus open surgery. Int J Med Robot 7: 131-7.

\section{5}

5. Chalikond

(2012)

Laparoscopic

robotic-assisted

pancreaticoduodenectomy: a case-matched comparison with open resection. Surg Endosc 26: 2397-402.

36. Hammill C, Cassera M, Swanstrom L, Hansen P (2010) Robotic assistance may provide the technical capability to perform a safe, minimally invasive pancreaticoduodenectomy. HPB 12: 198-200.

37. Walsh M, Chalikonda S, Saavedra JRA, Lentz G, Fung J (2011) Laparoscopic robotic assisted Whipple: early results of a novel technique and comparison with the standard open procedure. Surg Endosc 25: S221. 